\title{
Diário de um ano ruim, de J. M. Coetzee: a vertente crítica na estética do pós-modernismo
}

Diary of a bad year, by J. M. Coetzee: the critical stance on postmodernism aesthetics

Deivis Jhones Garlet Rosani Ketzer Umbach

Universidade Federal de Santa Maria - UFSM - Santa Maria - Brasil

Resumo: Este trabalho pretende analisar a obra Diário de um ano ruim, de J.M. Coetzee, em seus elementos formais e de conteúdo, sobretudo a partir da arquitetura material da obra e das relações entre as personagens. As escolhas formais do escritor remetem para elementos da estética do pós-modernismo, como o hibridismo dos gêneros, a metaficção e a forma rizomática, porém veiculadores de um conteúdo axiológico ético e humanista. Desse modo, a análise visa demonstrar como a obra, entendida em sua totalidade, se relaciona dialeticamente com a estética e a episteme pós-moderna, conservando elementos essenciais e superando a superficialidade experimental e temática criticada por autores como Jameson e Eagleton.

Palavras-chave: Coetzee. Pós-modernismo. Ética. Humanismo.

Abstract: This work aims to analyze the work Diary of a bad year, J.M. Coetzee, in their formal and content elements, especially from the physical work architecture and the relationships between the personages. Formal writer choices refer to elements of postmodernism aesthetics, as the hybridity of genres, the metafiction and rhizomatic way, but backers of an ethical and humanistic axiological content. Thus, the analysis aims to demonstrate how the work, understood in its entirety, relates dialectically with aesthetics and postmodern episteme, retaining essential elements and overcoming the experimental superficiality and thematic criticized by authors such as Jameson and Eagleton.

Keywords: Metaphor. Coetzee. Postmodernism. Ethic. Humanism. 


\section{Introdução}

A recente obra do escritor sul-africano J. M. Coetzee, Diário de um ano ruim, lançada em 2007, caracteriza-se por um elaborado amálgama entre formas não tradicionais de representação literária e um conteúdo que dialoga criticamente com a realidade concreta do mundo globalizado. Desde a disposição arquitetônica do texto, passando pelo hibridismo dos gêneros e a proposição semântica por meio de paradoxos, a obra instaura uma polissemia ímpar, a qual impede uma explicação unívoca. No entanto, é consenso que a estética de Diário de um ano ruim é permeada por características que a aproximam do pósmodernismo. Segundo a crítica literária Helena (2010, p. 49), a obra em apreço "utiliza-se em pauta incomum de alguns clichês em vigor na atualidade - tais como o hibridismo, a metaficção, o jogo de espelhos, o trabalho com a dobra e a forma rizomática, etc. executando-os para além do previsto pelas modalidades em voga".

De fato, todos os elementos listados pela pesquisadora se fazem presentes no texto de Coetzee, porém, como é pertinentemente salientado, de uma maneira idiossincrática, o que constitui um desafio ao trabalho de análise, uma vez que não será suficiente constatar tais características, mas antes elucidar-lhes o funcionamento no interior do universo ficcional e a relação que estabelecem com o contexto material. Diante da riqueza polissêmica da obra, engendrada tanto por seus elementos formais quanto pelos temáticos, necessitamos - ante o risco de recair na superficialidade teorética - delimitar um campo de análise, o qual, evidentemente, deve se inserir no âmbito das possibilidades ofertadas pela obra.

Desse modo, julgamos apropriado - uma vez que o texto se insere na estética do pós-modernismo expormos, brevemente, uma teorização da referida estética, de maneira a sedimentar a análise subsequente e justificar nossa proposta de estudo. Além disso, tal contextualização teórica, mesmo que sintética e de modo algum pretensiosa a ponto de abordar exaustivamente as diferentes correntes teóricas do fenômeno pós-moderno, faz-se necessária justamente pelas particularidades de compreensão do hodierno.

O pós-moderno e o pós-modernismo são definidos por Eagleton em termos de periodização histórica e de forma cultural, respectivamente. De acordo com o autor:

A palavra pós-modernismo refere-se em geral a uma forma de cultura contemporânea, enquanto o termo pós-modernidade alude a um período histórico específico. Pósmodernidade é uma linha de pensamento que questiona as noções clássicas de verdade, razão, identidade e objetividade, a ideia de progresso ou emancipação universal, os sistemas únicos, as grandes narrativas ou os fundamentos definitivos de explicação [...] Pósmodernismo é um estilo de cultura que reflete um pouco essa mudança memorável por meio de uma arte superficial, descentrada, infundada, autorreflexiva, divertida, caudatária, eclética e pluralista, que obscurece as fronteiras entre a cultura 'elitista' e a cultura 'popular', bem como entre a arte e a experiência cotidiana. (EAGLETON, 1998, p. 7 - grifos do autor).

Como bem esclarece o autor, a pósmodernidade, enquanto modelo epistemológico, nega uma série de conquistas históricas, confluindo para a negação da própria possibilidade da epistemologia, conforme podemos ler também em Giddens (1991, p. 163). Dessa forma, decreta inclusive o repúdio aos modelos de compreensão anteriores, como o materialismo dialético e o freudismo, segundo Jameson (1991, p. 40). Decorrente dessa linha de pensamento, afirma-se também o fim do indivíduo, da ética, do humanismo, da política emancipatória, enfim, da própria História. Desse posicionamento deriva o culto da ambiguidade, da indeterminação, do ceticismo, do relativismo, da descrença no potencial de ação do sujeito, conforme podemos ler em Eagleton (1998). Evidentemente, é preciso considerar a historicidade desse processo, com a evolução da estrutura econômica a um estágio denominado por Jameson (1991) de capitalismo tardio, no qual o fenômeno pós-moderno nada mais seria do que uma espécie de disfarce sofisticado do conservadorismo do capital.

Paralelamente, segundo a citação acima, o pósmodernismo estaria ligado à cultura, refletindo - como bem enfatiza o autor - "um pouco" tudo isso, com repercussões nem sempre promissoras para o 
artístico, agora também dominado pelo mercado. Nesse mesmo sentido é que Jameson (1991, p. 32) irá caracterizar o pós-modernismo como uma dominante cultural, cujas características mais nefastas seriam a falta de profundidade, tanto na teoria quanto na arte, o enfraquecimento da historicidade e o esmaecimento dos afetos.

Nesse ponto, precisamos ressalvar a proposição sobre o pós-modernismo enfatizada por Hutcheon (1991), embora a autora concorde com a visão de Jameson (1991) e de Eagleton (1985) de que toda postura frente ao pós-moderno é necessariamente um posicionamento político. A autora, por outro lado, enfatiza a função da paródia, da metaficção historiográfica, da valorização da diferença, da ambiguidade, da indeterminação, entre outros, como elementos de um poderoso questionamento aos antigos valores - o que, diga-se de passagem, de fato ocorre em certas manifestações artísticas do pósmodernismo. Entretanto, o fato é que mesmo nas concepções dialéticas em relação à pós-modernidade (tanto histórica quanto cultural) os autores reconhecem os pontos positivos do pensamento e da arte pósmoderna, tomando o cuidado de não generalizar em um todo absoluto, monolítico, a crítica e os objetos artísticos. Por isso, a referência a uma dominante cultural, sobremaneira aquela ditada pelas regras do mercado. Assim, é evidente que há obras - pensamos aqui no que se refere à literatura - que incorporam características do pós-moderno (tanto histórico quanto cultural) de maneira a questionar a própria pósmodernidade. Certamente, autores como J. M. Coetzee, José Saramago e Raul Piglia, para citarmos apenas alguns expoentes, não apresentam uma literatura marcada pelas características nefastas do fenômeno pós-moderno, mas exatamente o contrário. Isso, todavia, não invalida o fato de que constituem, provavelmente, exceções honrosas em um espectro maior de superficialidade teórica e artística.

Assim, as características mais salientes do pósmodernismo, como o paradoxo, a ambiguidade, a ironia, a indeterminação e a contingência, segundo Coutinho (2008, p. 163), além da polifonia narrativa, da fluidez genológica, da modelização paródica da
História e da história, da metaficção e da autorreflexividade, conforme Arnaut (2002, p. 357), podem desempenhar uma função estética para além do experimentalismo incauto, fomentando uma obra complexa, polissêmica e extremamente contemporânea na acepção de Agamben (2009), deixando entrever não as luzes do progresso, mas os problemas mais candentes da época. Nesse sentido, Diário de um ano ruim constitui-se por formas ligadas ao pós-modernismo lúcido, questionador, contemporâneo, aliando a forma não convencional de representação ao conteúdo de proposição ética.

Assim sendo, na análise da obra em questão não nos é possível ignorar novos paradigmas de análise da arte, como as teorias de Deleuze e Guattari (1995) e Eco (1976), mas igualmente é necessária a metodologia do materialismo dialético, de modo que nos seja possível explicar a totalidade abarcada pelo texto, a função axiológica dos constituintes estéticos e extraestéticos no universo ficcional e sua relação dialética com o real concreto, e assim não escorregar para uma explicação que idolatre, sem questionamento, a ambiguidade e a indeterminação. Segundo Eagleton (1998, p. 21), "Captar a forma de uma totalidade exige raciocínio rigoroso e cansativo, o que vem a ser uma das razões de por que aqueles que não têm necessidade de fazê-lo venham a se maravilhar com a ambiguidade e a indeterminação". Assim sendo, parece-nos que não podemos faltar ao compromisso de tentar compreender a obra literária em sua efetiva complexidade e posição axiológica.

A obra de Coetzee, em nossa avaliação, solicita uma análise que elucide a relação entre a sua arquitetura ligada à estética do pós-modernismo e o conteúdo de crítica social, aquela realizando este. Esta é a hipótese de estudo que aventamos, ou seja, a de que os elementos formais de matiz pós-modernista estruturam uma proposição crítica - no nível do conteúdo - ao mundo globalizado, apresentando como postulado a ação ética e confluindo ao encontro do modelo de arte defendido por Jameson (1991, p. 79).

Diário de um ano ruim apresenta uma arquitetura material que "questiona a organização tradicional do livro de ficção", conforme Santiago 
(2010, p. 217). Dividido em duas partes, a primeira intitulada "Opiniões Fortes" e a seguinte "Segundo Diário" - alcunhado pela personagem Anya de "Opiniões brandas", referem-se aos ensaios curtos locados na parte superior de cada página, de cunho público / político e privado / particular, respectivamente. A primeira parte comporta 31 capítulos e 167 páginas da obra, ao passo que a segunda é formada por 24 capítulos e 65 páginas. A ênfase na primeira parte, ao menos quantitativamente, pode ser aventada na hipótese de as "Opiniões Fortes" constituírem parte do livro encomendado ao personagem escritor que se assina JC - possivelmente um alter-ego do autor empírico - para expressar sua opinião sobre os problemas do mundo contemporâneo; ou à hipótese da progressiva mudança de opinião ocorrida no escritor JC após seu encontro com Anya, que também sofre um processo de transformação, dada a interação dialógica entre eles. Todavia, o que permanece é o caráter de ensaios destes textos que ocupam o bloco superior em cada página, inclusive com a inserção de notas de fim de texto, simulando escritos não ficcionais.

Além destes curtos ensaios, nos quais se discute em forma de paradoxo diversos temas, a materialidade do livro apresenta um segundo bloco, logo abaixo dos ensaios, no qual a personagem JC relata, em primeira pessoa, seu encontro com Anya, a bela vizinha, nas Torres Sydenham, em Sidney, Austrália, e por quem desenvolve imediata paixão. Convida-a para digitar seu manuscrito encomendado por um editor alemão, estreitando as relações entre os dois a ponto de a moça sugerir-lhe que não escreva sobre política ou, inclusive, que discorde de certas opiniões contidas no manuscrito, o que viabiliza mudanças de comportamento das personagens.

Um terceiro bloco, na parte inferior da página, expõe o relato de Anya, também em primeira pessoa, de sua vida com Alan, seu namorado, e as conversas que vão travando a respeito do velho escritor e seus manuscritos.

Essa estrutura (embora nem sempre com os três blocos), também se diferencia da convenção tradicional do livro de ficção pelo fato de os enunciados não se encerrarem sempre na página em que iniciam, ocorrendo frequentemente a separação silábica que remete para a página seguinte. Diante de tal singular arquitetura, o leitor poderá escolher entre várias formas de manuseio, de leitura. Por exemplo, é lícito (mas não recomendável) ler somente os ensaios, assim como somente a trama propriamente romanesca. Também é possível ler de maneira tradicional, linha após linha - e ignorar a continuidade do bloco, que, todavia, será lido na sequência, com o risco de se tornar um tanto confuso o seu entendimento; ou seguir as indicações de continuidade do enunciado de cada bloco, em um contínuo ir para frente, voltar atrás nas páginas do livro.

De fato, parece-nos que a estrutura permite diferentes modos de entrada e de saída, sendo aberta à fruição do leitor, em certa medida como o rizoma de Deleuze;Guattari (1995). Ao mesmo tempo, instala uma ampla gama de possíveis interpretações, abrindo a obra para um horizonte no qual o leitor é convidado a participar, em suma, um objeto estético a ser acabado, pois expõe "... estruturas imprevistas, fisicamente irrealizadas...", que se podem “... definir como "obras em movimento"'. (ECO, 1976, p. 51 grifo do autor).

Rizoma, obra aberta, obra em movimento: certamente Diário de um ano ruim apresenta uma forma arquitetônica - tanto materialmente, da disposição tipográfica, quanto do próprio enredo e da hibridização dos gêneros - que a situa nesses conceitos, conforme vimos brevemente na exposição acima. É preciso reconhecer que a específica organização material da obra, com sua abertura e convite ao leitor para efetivá-la obedece, ainda e apesar, ao projeto consciente do autor. Segundo Eco:

O autor oferece, em suma, ao fruidor uma obra a acabar: não sabe exatamente de que maneira a obra poderá ser levada a termo, mas sabe que a obra levada a termo será, sempre e apesar de tudo, a sua obra, não outra, e que ao terminar o diálogo interpretativo ter-se-á concretizado uma forma que é a sua forma, ainda que organizada por outra de um modo que não podia prever completamente: pois ele, substancialmente, havia proposto algumas possibilidades já racionalmente organizadas, orientadas e dotadas de exigências orgânicas de desenvolvimento. (ECO, 1976, p. 62 - grifos do autor) 
Com efeito, a estrutura material de Diário de um ano ruim, embora aberta e de múltiplas possibilidades de realização, distancia-se de um experimentalismo virtuose e superficial, ou do "Tecnonarcisismo" criticado por Deleuze;Guattari (1995, p. 45), ao entremear os três blocos em uma trama romanesca, na qual todos se relacionam, por exemplo, com o comentário de Anya sobre os manuscritos, que supostamente constituem os curtos ensaios; a relação do casal, Anya e Alan, é perturbada pelo trabalho de Anya com JC; ou, muito simplesmente, verificam-se simetrias de conteúdo, a exemplo do capítulo 24 das "Opiniões fortes", intitulado "Da direita e da esquerda", - qual aborda a espionagem das agências de inteligência internacionais $e$, simetricamente, no terceiro bloco, Alan revela para Anya que está espionando JC com um programa de computador. Embora o leitor possa escolher a maneira com que irá ler a obra, é evidente que o autor fornece coordenadas que consistem na percepção da unidade dos três blocos na totalidade da obra. Compreender isso constitui condição sine qua non para uma explicação do objeto de estudo, pois de outra maneira corremos o risco de uma análise de superfície, semelhante àquela criticada por Jameson (1991, p. 40).

Desse modo, o livro de Coetzee, para além de um simples exercício de hibridização dos gêneros, de uma inaudita subversão dos moldes da narrativa de fiç̧ão, da exposição de identidades fragmentadas, da indeterminação ou da ambiguidade, em sua forma aberta e em movimento, exige a consideração de sua unidade tripartida, como afirma Santiago (2010).

Dessa maneira, nos indagamos que elemento permite unir a tríade? Evidentemente, há que se hipostasiar a relação entre os três blocos como mencionamos acima, pela disposição do próprio enredo e dos temas dos ensaios. Todavia, pensamos que o todo romanesco é permeado pela ética, no sentido humanista, pela qual as personagens se revelam e se transformam; pela qual as ações são mensuradas; pela qual o próprio desenlace do triângulo amoroso se define; enfim, como, do primeiro bloco, os ensaios, ao relato em forma de diário de JC e ao terceiro bloco, o relato de Anya e seu namorado, a ética e a antiética, a moralidade e a imoralidade acabam por constituir a tensão que movimenta o universo ficcional, tanto nas questões públicas / políticas, quanto nas privadas / individuais. Em consonância com esse modo de pensar, Santiago (2010, p. 220) ressalta a importância do estudo da obra em sua "... estética drapejada pela ética...", assim como Axt (2010, p. 78) ressalta a ética que "não prescinde jamais dos referenciais clássicos e humanistas, que permeiam toda a obra."

Nesse sentido, a progressiva caracterização das personagens, que constituem consciências independentes de uma voz narrativa monológica, e se autorrevelam por meio das relações dialógicas, em acordo com a acepção bakhtiniana de dialogismo, evidencia paulatinamente os polos de postura ética e de postura antiética no romance. Segundo Bakhtin (2010, p. 292, grifo do autor), "Representar o homem interior como o entendia Dostoiévski só é possível representando a comunicação dele com um outro. Somente na comunicação, na interação do homem com o homem revela-se o 'homem no homem' para outros e para si mesmo". No romance de Coetze, essa dimensão dialógica verifica-se amplamente, com as personagens se revelando na interação dialógica com o outro, a exemplo de JC e Anya, Anya e Alan e, também, no encontro das três. As mudanças de pensamento e de ações dão-se pelo processo de autorrevelação pelo diálogo concreto, no qual ficamos a conhecer cada uma das personagens.

O escritor JC, ou Señor C, conforme Anya o denomina, constitui-se como um intelectual idoso, com mais de 80 anos, que sofre do mal de Parkinson. Além disso, já é uma notoriedade no meio literário, tendo prestígio e riqueza advinda de sua atividade como escritor profissional. Suas opiniões sobre os temas controversos da atualidade, contidas, sobretudo, nos curtos ensaios na parte superior das páginas, acentuam uma avaliação crítica de fenômenos os mais diversos, sob um matiz ético, o qual incorpora as noções de equidade e de justiça, bem como de humanismo, conforme podemos ler em sua opinião a respeito do terrorismo, na qual, por meio de constantes paradoxos, constata a aversão do ocidente ao 
terrorismo, ao passo que o mesmo (o ocidente) não critica bombardeios efetuados por tropas regulares sobre civis. Após longa argumentação, na qual desvela a supremacia bélica de países ocidentais e de Israel, conclui, referindo-se aos terroristas, que "Diante de tal adversário, como alguém pode preservar a própria honra senão com desespero, extravagantemente jogando fora a própria vida?" (COETZEE, 2008, p. 39). O argumento não é uma simplória apologia do terrorismo, mas um chamado a analisar a questão humanamente, buscando uma explicação, e não uma justificação para tais atos.

Além disso, JC deixa transparecer uma postura de valorização e de respeito pelo outro, de sentimentos humanitários também no léxico de sua fala, a qual é extremamente invulgar, educada e suave, como no momento em que descreve o primeiro encontro com Anya, referindo-se ao seu vestido muito curto com a sutil expressão de "surpreendente brevidade" (COETZEE, 2008, p. 7). Efetivamente, a conduta e o léxico expressivo de JC condizem com um cavalheirismo um tanto escasso na sociedade atual. Veja-se a linguagem empregada ao falar de Anya:

Ela gosta de se apresentar como filipina, uma pequena trabalhadora provisória filipina. $\mathrm{Na}$ verdade, ela nunca viveu nas Filipinas. Seu pai era um diplomata australiano que se casou com uma mulher que ele conheceu num coquetel em Manila, esposa prestes a se divorciar de um incorporador de propriedades. Até seu pai fugir com a secretária e abrir um restaurante em Cassis (grande escândalo), Anya frequentou escolas internacionais por toda parte (Washington, Cairo, Grenoble). Os benefícios que recebeu dessa escolaridade internacional não são claros. Ela fala francês com um sotaque que os franceses provavelmente acham charmoso, mas nunca ouviu falar de Voltaire. Ela acha que Kyoto é Tokio digitado errado. (COETZEE, 2008, p. 77 -79 , grifo nosso)

JC revela o passado de Anya, seu perambular pelo mundo globalizado, sua origem "mestiça" e sua limitada cultura de maneira similar a um eufemismo, note-se a expressão sublinhada, também porque influenciado por seu amor pela moça. Porém, um amor casto, platônico mesmo, embora ainda assim o amor em um sentido sexual que, todavia, ele não expressa em palavras consideradas imorais ou vulgares:

Cada palavra que ela diz é encantadora, ela pode dizer o que lhe vier à cabeça. Da mesma forma, como tudo o que ela faz tem de ser engraçadinho, ela tem liberdade de fazer o que sentir vontade. Um modo de pensar de criança mimada. O problema é que ela não é mais criança. Isso deixa um gosto perturbador. (COETZEE, 2008, p. 55)

O velho escritor claramente está apaixonado pela jovem Anya, mas, em momento algum deixa transparecer em seus pensamentos, atos e falas uma postura indelicada, excessivamente erótica a ponto de se tornar obscena ou despudorada.

Essa linguagem que identificamos com uma postura educada, cavalheiresca, ética no sentido de respeitar a alteridade e a dignidade do homem, resta ainda mais evidente quando em diálogos. Por ocasião de uma discussão com Anya sobre a honra e a desonra, a moça afirma, ironicamente, sua incapacidade de pensar a questão, sugerindo que JC a considerava uma "cabeça oca", ao que o escritor responde que nunca dissera tal coisa. Então Anya responde:

Não, é verdade, nunca disse, é educado demais para isso; mas pensou. Pensou desde o primeiro minuto. Que linda bunda, o senhor pensou, uma das bundas mais lindas que já vi. Mas nada ali em cima. Se eu fosse mais moço, o senhor pensou, ia adorar cair em cima dela. Confesse. Foi isso que o senhor pensou. Mais ou menos. Foi mais ou menos isso que eu pensei. Se bem que não nesses termos. (COETZE, 2008, p. 105 - grifo do autor)

Aqui, a própria Anya reconhece a educação de JC, mas insiste no que ele teria pensado sobre seu corpo e de uma relação sexual, porém com vocabulário inadequado ao escritor, como ele próprio o afirma com a expressão "não nesses termos".

Em síntese, JC é um narrador-personagem que se conduz de maneira ética, desde as questões políticas até as privadas, como nos ensaios e no relacionamento com Anya, e isso se concretiza por uma linguagem que se harmoniza com o tom de moralidade humanista de sua personalidade. Além disso, as demais personagens contribuem para a percepção da ética de JC, quer pelo contraste, quer pelo reconhecimento de suas qualidades. A personagem Alan, namorado de Anya, afirma que JC não entende a modernidade, que vê em tudo um dilema moral, ao passo que o mercado está além da questão ética. Ao falar de JC, Alan ajuda a revelar a 
postura ética do idoso escritor - entendida como arcaica / velha - e se autorrevela como sua antítese moderna / nova. De fato, a personagem Alan encarna a posição antiética e antitética (burguesa e pouco humanista) no romance, ligada ao mundo da globalização.

O namorado de Anya é apresentado como um consultor de investimentos - um self made man inescrupuloso e ganancioso, o qual justifica suas ações em termos teleológicos. Ao saber do trabalho de Anya, imagina diversas formas de obter dividendos de forma imoral e ilegal, acusando JC de estar usando sua namorada com finalidades supostamente sexuais. Sua conduta antiética reflete-se também na linguagem que emprega, evidenciando um distanciamento radical da educada postura de JC, ao afirmar para a namorada: "Porque ele tem sonhos sacanas com você chupando o pau sujo e velho dele e depois o chicoteando com um relho. E o que significa isso tudo? Propaganda enganosa. Convites ilícitos. Assédio sexual. A gente vai pegar esse cara!" (COETZEE, 2008, p. 73).

Alan deseja, de qualquer forma, angariar lucros da relação de trabalho estabelecida entre Anya e JC, e a linguagem vulgar ratifica sua conduta distante de uma ética humanista, distante da educação cavalheiresca de JC, linguagem reiteradamente vulgar como ao referir-se a Anya, "Minha Princesa da Prexeca. Minha Baronesa da Boceta" (COETZEE, 2008, p. 94).

Prosseguindo em seu plano desonesto de lucrar a qualquer preço, Alan introduz um programa de computador para espionar os arquivos de JC, planejando usar o capital que o velho escritor possui em uma conta bancária e que está destinado a uma instituição de caridade para animais, segundo o testamento. Tal plano é revelado pelo próprio Alan em uma recepção no apartamento de JC, depois de se embriagar. Ao mesmo tempo, envergonha e humilha Anya com uma postura indecorosa e sugestões obscenas, sempre com um linguajar compatível:

Ela defendeu e eu dei ouvidos à defesa dela, disse Alan. Opa, escapou, o gato subiu no telhado. Eu ouvi a defesa dela e desisti. É, verdade seja dita, Juan, era eu, eu era o semvergonha que ia roubar você. Mas não roubei.
Por causa da minha dama aqui. Minha dama adorável de boceta doce, doce. (COETZEE, 2008, p. 188)

De fato, Alan não rouba o capital do velho escritor por causa da defesa de Anya. Porém, sua conduta antiética, assim como sua linguagem vulgar, arrefece a relação com a namorada, a qual - também por influência da ética de JC - não aceita mais viver com Alan, partindo para a casa da mãe.

Anya, por seu lado, constitui-se, em nosso entendimento, como a protagonista do romance. Jovem de 29 anos, que se autoproclama filipina e que representa o homem médio do mundo globalizado, é inicialmente frívola e ligada às futilidades, mas aos poucos vai se transformando, sobremodo pelo contato com JC e o contraste deste para com seu namorado. Exemplar da transformação dialógica da personagem é a mudança de linguagem que informa também a mudança de atitude perante o mundo. Logo no início do romance, Anya assim se refere a si: "Ao passar por ele carregando minha cesta de roupa suja, faço questão de sacudir o traseiro, meu delicioso traseiro, envolto em jeans justos. Se eu fosse homem, não conseguiria tirar os olhos de mim" (COETZEE, 2008, p. 33). Percebe-se uma concessão de importância vital a exterioridade sexual de seu corpo, em uma atitude provocativa, expressa por um léxico um tanto vulgar. Anya, no início do romance, é apenas uma mulher preocupada com a aparência física e com o sexo.

No entanto, na relação que vai travando com JC, ao ler e discutir seus manuscritos, ao conviver com um homem de índole ética, vai percebendo a desonestidade, a imoralidade e a vulgaridade de Alan, até culminar no rompimento do casal. Efetivamente, podemos afirmar que a trama romanesca forma um triângulo amoroso, no qual Anya oscila de uma relação com um sujeito assaz "trapaceiro" para uma relação mais intensa - mesmo que não sexual - com o escritor JC, e sua postura ética, afirmando que "Provavelmente eu ainda estaria com Alan, se não fosse o senhor" (COETZEE, 2008, p. 214). Ou, de modo mais incisivo:

O senhor me abriu os olhos, isso eu digo. Me mostrou que existia um outro jeito de viver, tendo ideias e expressando essas ideias com clareza e tal. (...) Mas talvez, numa outra vida, se nossas idades forem mais compatíveis, o senhor e eu vamos poder morar juntos e vou 
poder ser sua inspiração. Sua inspiração residente. O senhor gostaria disso? Poderia sentar em sua mesa e escrever, e eu cuidaria do resto. (COETZEE, 2008, p. 215)

Seria uma declaração de amor? Anya não opta, nesse triângulo amoroso, por JC, de modo algum pelo seu potencial físico-sexual; de maneira alguma pelo seu capital ou por sua notoriedade midiática, mas exatamente pela sua forma de agir educada, cavalheira, sensível, humana - em síntese, ética. Ao romper com Alan, Anya já não se utiliza de um léxico obsceno para se expressar, assinalando a sua mudança de postura perante o outro e o mundo. Exemplar nesse sentido é a carta que escreve para JC e que encerra com as seguintes palavras:

Tudo isso eu vou prometer para ele e segurar apertado a mão dele e dar um beijo na testa dele, um beijo de verdade, só para ele lembrar do que está deixando para trás. Boa noite, Señor C, vou sussurrar no ouvido dele: bons sonhos e revoadas de anjos e tudo o mais. (COETZEE, 2008, p. 236)

Ela cumpre a promessa? O desfecho do romance não permite uma afirmação peremptória permanece em aberto, a ser acabado pela sensibilidade do leitor, em consonância com a estrutura física rizomática e em movimento - mas, a julgar pela ênfase que a narrativa põe no agir ético, humanista, pode-se imaginar que sim.

Desse modo, Diário de um ano ruim apresenta uma forma arquitetônica material que o aproxima da estética do pós-modernismo, ao mesmo tempo em que - conteúdo dialoga com a pós-modernidade. A hibridização dos gêneros, para além de um exercício de experimentalismo formal, permite ao escritor empírico expressar seus sentimentos em relação aos problemas do mundo globalizado no terreno que lhe é conhecido: a ficção romanesca. Habilmente, os três blocos se interligam e se relacionam reciprocamente para enfatizar uma proposição axiológica em defesa do agir ético, sobremodo no sentido humanista. A ética, de fato, constitui-se como o ponto de mediação do romance, pela qual circulam e são avaliadas as opiniões (ensaios), as personagens, a vida pública e a vida privada. Pode-se mesmo afirmar que o romance atinge a contemporaneidade de Agamben (2009), aproxima-se de uma arte engajada, mas sem dogmatismo ou proselitismo, defendida por Eagleton (1998) e Jameson (1991) contra uma dominante cultural pós-moderna atrelada ao consumismo superficial e inumano.

Podemos sintetizar o proposto até aqui com o seguinte organograma, o qual não pretende exaurir os elementos constituintes do universo ficcional, mas apresentar sinteticamente nossa compreensão e explicação da obra que ora analisamos (Figura 1).

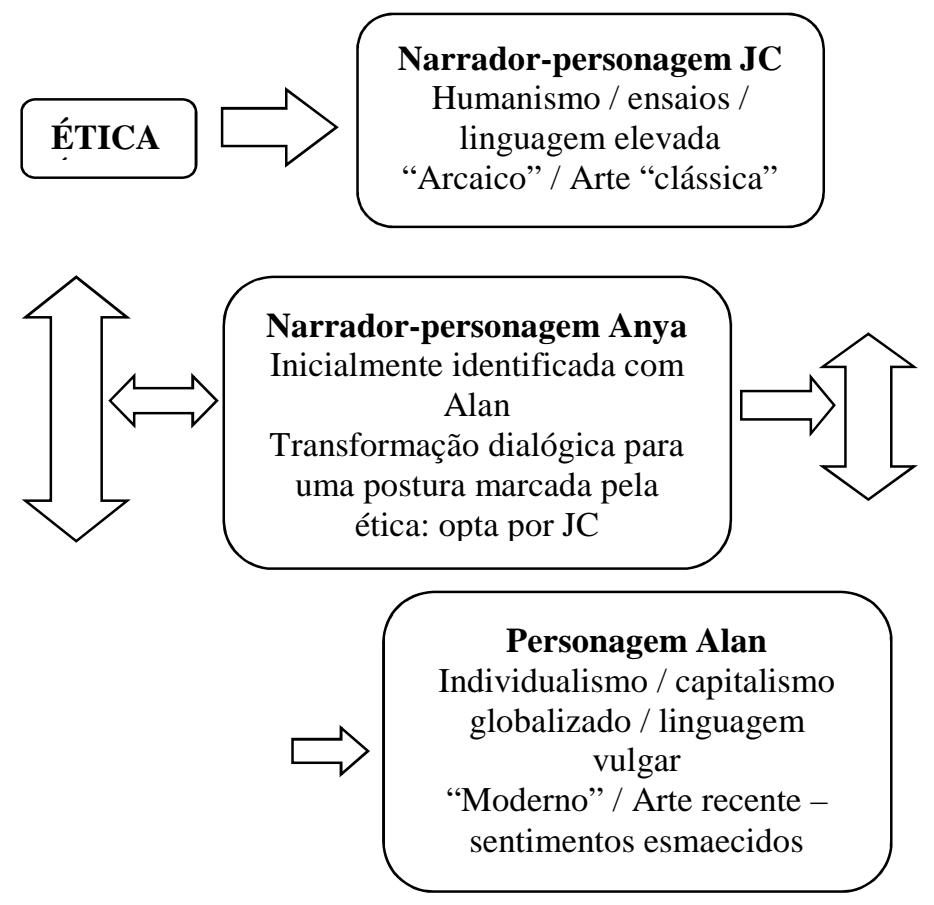

Figura 1

Considerando o organograma, podemos entendê-lo em sua relação dialética com a realidade concreta, refratando modos de compreender a ANTIÉTICA no agir nela. Assim, Anya representa a possibilidade do homem comum de transformar sua atitude excessivamente individualista, atrelada aos ditames do capital, pouco solidária ou ligada a trivialidades do senso comum, para uma postura marcada pelo compromisso ético humanista. Ao mesmo tempo, reivindica uma arte, em especial a literatura, igualmente restauradora dos sentimentos mais sublimes do homem, como podemos ver no apego de JC aos escritores russos do século XIX, notadamente Tolstói e Dostoiévski. 
Nessa linha de reflexão, questões caras aos teóricos marxistas da pós-modernidade, como a necessidade de valorizar o sujeito, a razão, a ética, a política, a profundidade, de sentimentos e de uma explicação da totalidade concreta, são alcançados pela obra em apreço, como tentamos demonstrar. Modelares, nesse sentido, são as passagens dos ensaios curtos em que JC discorre sobre a música do século XIX, dotada de profundo sentimento, e a música atual, na qual é difícil determinar os princípios que a animam, concluindo pela assertiva de que "O ruim expulsa o bom ..." (COETZEE, 2008, p. 144). Quanto à arte literária, o narrador-personagem JC critica a literatura recente, incapaz de tocar o sentimento humano, afirmando que "Para esse toque de profundidade, volto aos clássicos, aos episódios que numa era passada seriam chamados de pedras de toque, pedras que se tocava para renovar nossa fé na humanidade" (COETZEE, 2008, p. 201).

De fato, Diário de um ano ruim é uma obra que se vale da estética do pós-modernismo, como em sua forma material, em sua hibridização de gêneros, seus múltiplos narradores, sua abertura e seu movimento, mas não recai na arte superficial e comercial criticada pelos teóricos marxistas. Pelo contrário, exige uma complementação crítica que perceba a proposição axiológica do agir ético, tanto na vida privada (expresso no triângulo amoroso do universo ficcional), quanto na vida pública (expresso nos ensaios da parte superior do livro). Percebendo esses polos que norteiam as ações, a ética (JC) e a antiética (Alan), podemos explicar a obra em sua totalidade significativa, com Anya evidenciando a possibilidade de uma transformação do sujeito pós-moderno em direção a uma postura humanista. Dessa forma, a posição axiológica contida no romance dialoga criticamente com a realidade concreta do mundo globalizado, ou pós-moderno. Afinal, conforme é apresentada no capítulo 24, intitulado "De Dostoiévski", a ética proposta se assenta na figura de Cristo, centrada em um amor abnegado, tão cara ao escritor russo, além do elogio à Tolstói, concluindo enfaticamente que "Com o exemplo deles somos artistas melhores; e como artistas melhores não quero dizer mais hábeis, mas eticamente melhores." (COETZEE, 2008, p. 236 - grifo nosso).

Finalmente, Diário de um ano ruim é, par excellence, uma obra literária que se posiciona axiologicamente em prol da ação ética humanista, além de outras questões não abordadas neste curto trabalho. Atento aos reclames de uma estética do pósmodernismo, não se esgota em superficialidades, em experimentalismos e outras pirotecnias formais, mas utiliza-as como forma de dar voz a um conteúdo de proposição social, de crítica contundente ao homem e ao mundo globalizado, pós-moderno - postulando uma valorização da ética de matiz humanista e harmonizando-se com a crítica de Eagleton (1998) e de Jameson (1991) ao próprio fenômeno do pósmodernismo e do pós-moderno.

\section{Referências}

AGAMBEN, G. O que é o contemporâneo? e outros ensaios. Tradução Vinicius Honesko. Chapecó: Argos, 2009.

ARNAUT, Ana Paula. Post-modernismo no romance português contemporâneo: fios de Ariadne, máscaras de Proteu. Coimbra: Almedina, 2002.

AXT, Gunter. J. M Coetze e o chamamento à velhice na contemporaneidade fragmentada. In: Philia \& Filia. Vol. 1. Set/Dez, N², Porto Alegre, UFRGS, 2010.

BAKHTIN, M. Problemas da poética de Dostoiévski. Tradução de Paulo Bezerra. 5. Ed. Rio de Janeiro: Forense Universitária, 2010.

COETZEE, J. M. Diário de um ano ruim. Tradução de José Siqueira. São Paulo: Cia das Letras, 2008.

COUTINHO, Eduardo F. Revisitando o Pós-moderno. In: GUINSBURG, J.; BARBOSA, A. (org). O Pósmodernismo. São Paulo: Perspectiva, 2008.

DELEUZE, G.; GUATTARI, F. Introdução: Rizoma. In: Mil Platôs. Vol. 1. Tradução de Ana Lúcia de Oliveira, Aurélio Guerra Neto e Celia Pinto Costa. São Paulo: Editora 34, 1995.

EAGLETON, Terry. As ilusões do pós-modernismo. Tradução de Elizabeth Barbosa. Rio de Janeiro: Zahar, 1998.

Capitalismo, modernismo e pós-modernismo. In: Crítica Marxista. Tradução de João Martins Filho. Vol. 1. N². São Paulo, UNICAMP, 1995. 
ECO, Umberto. A poética da obra aberta. In: Obra aberta: forma e indeterminação nas poéticas contemporâneas. Tradução de Sebastião Leite. São Paulo: Perspectiva, 1976.

GIDDENS, A. As consequências da modernidade. Tradução de Raul Filker. São Paulo: UNESP, 1991.

HELENA, Lucia. Cristais da memória em J. M. Coetze: Reflexões em torno do estar à margem e do paradoxo em Diário de um ano ruim. In: Philia \& Filia. Vol. 1. Jul/Dez, N², Porto Alegre, UFRGS, 2010.
HUTCHEON, Linda. Poética do Pós-modernismo. Tradução de Ricardo Cruz. Rio de Janeiro: Imago, 1991.

JAMESON, F. Pós-modernismo: a lógica cultural do capitalismo tardio. São Paulo: Ática, 1991.

SANTIAGO, Silviano. J. M. Coetze, Resenha de Diário de um ano ruim. In: Philia \& Filia. Vol. 1. Jul/Dez, Nº 2, Porto Alegre, UFRGS, 2010.

\section{COMO CITAR ESSE ARTIGO}

UMBACH, Rosani Ketzer; GARLET, Deivis Jhones. Diário de um ano ruim, de J. M. Coetzee: a vertente crítica na estética do pós-modernismo. Signo, Santa Cruz do Sul, v. 41, n. 72, out. 2016. ISSN 1982-2014. Disponível em: $<$ https://online.unisc.br/seer/index.php/signo/article/view/7218>. Acesso em: doi: http: //dx.doi.org/10.17058/signo.v41i72.7218. 